\title{
Damage Identification of Bridge Based on Chebyshev Polynomial Fitting and Fuzzy Logic without Considering Baseline Model Parameters
}

\author{
Yu-Bo Jiao, Han-Bing Liu, Yong-Chun Cheng, and Ya-Feng Gong \\ Department of Transportation, Jilin University, No. 5988, Renmin Street, Changchun, Jilin 130025, China \\ Correspondence should be addressed to Ya-Feng Gong; gongyf@jlu.edu.cn
}

Received 15 August 2012; Accepted 16 February 2013

Academic Editor: Reza Jazar

Copyright ( 2015 Yu-Bo Jiao et al. This is an open access article distributed under the Creative Commons Attribution License, which permits unrestricted use, distribution, and reproduction in any medium, provided the original work is properly cited.

\begin{abstract}
The paper presents an effective approach for damage identification of bridge based on Chebyshev polynomial fitting and fuzzy logic systems without considering baseline model data. The modal curvature of damaged bridge can be obtained through central difference approximation based on displacement modal shape. Depending on the modal curvature of damaged structure, Chebyshev polynomial fitting is applied to acquire the curvature of undamaged one without considering baseline parameters. Therefore, modal curvature difference can be derived and used for damage localizing. Subsequently, the normalized modal curvature difference is treated as input variable of fuzzy logic systems for damage condition assessment. Numerical simulation on a simply supported bridge was carried out to demonstrate the feasibility of the proposed method.
\end{abstract}

\section{Introduction}

Bridge structures have endured progressive deterioration due to vehicle load and aging of material under the effect of external environment. In addition, the frequent occurrence of natural disasters could also cause damage and further accelerate the deterioration of bridge condition. Therefore, the damage assessment of bridge has attracted great interest of many researchers $[1,2]$.

Vibration-based damage identification method has been widely applied in the past few decades $[3,4]$. Theoretical background of this method is that modal parameters (frequency, mode shape, etc.) are functions of physical properties (stiffness, mass, etc.) of bridge. Therefore, the changes of modal characteristics can be treated as the damage indicators. The commonly used modal parameters for damage identification include natural frequency, mode shape, and their derivatives, such as mode shape curvature, modal strain energy, and modal flexibility [5-9].

Among these modal characteristics, natural frequency has no relation with measuring positions and can be measured most conveniently and accurately. However, the frequency-based method possesses several apparent drawbacks.
For instance, it is inferior sensitive to minor damage, and it is easily affected by environment [10]. Additionally, the simply supported reinforced concrete bridges are spatial symmetric structures. Natural frequency cannot distinguish damage at symmetric locations in these symmetric structures.

Comparing with natural frequency, mode shape and its derivatives contain the spatial information with respect to location of damage, and they are found to be better indicators for damage identification. The modal curvature is recognized as a more advanced damage indicator which is calculated from the displacement mode shape and firstly proposed by Pandey et al. [7]. It is found that the absolute changes in the curvature mode shapes between undamaged and damaged structures can effectively locate the damage region for cantilever and simply supported beam model. The changes in the curvature mode shape increase with increasing size of damage. However, this method requires the baseline data from intact structures. This baseline model data can be obtained by finite element simulation. In actual simulation, the accuracy of finite element model is affected by temperature because the elastic modulus of concrete is temperature dependent [11]. However, the modulus of elasticity versus temperature curve for concrete is unclear and complicated 
$[12,13]$. If their relationship is not reasonable to consider, it will lead to incorrect result for damage identification.

To avoid this difficulty, several researchers have conducted effective work for damage detection without baseline model data. Ratcliffe [14] proposed a modified Laplacian operator-based method for $1 \mathrm{D}$ beam, which determines the damage location through a cubic curve fitting for the modal data obtained only from the damaged structure. Wu and Law [15] proposed a damage localization method based on uniform load surface (ULS) curvature for 2D plates, which can identify the damage using only the modal characteristics of damaged state if a gapped-smoothing technique is applied. Yoon et al. [16] extended the 1D gapped-smoothing method to the $2 \mathrm{D}$ gapped smoothing method for the damage identification of plate. And the baseline data of undamaged structure are not needed. Zhong and Oyadiji [17] presented a novel approach for crack detection based on difference between two sets of detail coefficients obtained by stationary wavelet transform without requiring the modal data of undamaged beam as a baseline. Yoon et al. [18] extended the gapped smoothing method for identifying the location of structural damage in a beam by introducing the global fitting method, which uses the modal shape data of damaged structure with an assumption that the undamaged structure is homogeneous and uniform. Cao and Qiao [10] adopted a novel Laplacian scheme for modal curvature-based damage identification to improve the anti-noise ability of standard Laplace operator. Rodríguez et al. [19] presented a Baseline Stiffness Method (BSM) to locate and evaluate the magnitude of structural damage whose baseline state is unknown.

Modal curvature can realize the damage localization and qualitatively determine the damage degree. But it is not suitable for quantitative identification. Artificial neural networks (ANNs) have been utilized by many researchers to identify damage location and severity [20-25], as they can achieve the nonlinear mapping between the inputs and outputs from certain samples training. Ko et al. [20] developed a three-stage scheme for damage detection of the cable-stayed Kap Shui Mun Bridge. ANNs are used in the first and third stage for damage alarming and specific damaged member(s) identification. Sahin and Shenoi [21] presented a damage detection algorithm using a combination of global (changes in natural frequencies) and local (curvature mode shapes) vibration-based analysis data as input in ANNs for location and severity prediction of damage in beam-like structures. Lee et al. [22] proposed an ANNs-based damage detection method using the differences or the ratios of the mode shape components as the input variables, which can effectively consider the modeling errors in the baseline finite element model. Bakhary et al. [23] proposed a statistical approach which takes the effect of uncertainties into account in developing an ANNs model.

ANNs can be able to predict an output pattern when they recognize a given input pattern, but there exists an inherent inability to represent knowledge acquired by the network in an explicit form. That is the "black box" problem of ANNs [26, 27]. Fuzzy systems allow for easier understanding because they are expressed in terms of linguistic variables $[28,28]$. And they are finding increasing use in structural damage identification. Ganguli et al. $[29,30]$ adopted the natural frequency and modal shape curvature as the input of fuzzy logic systems and genetic fuzzy logic systems for the damage detection of helicopter rotor blades. Zhao and Chen [31] proposed a method based on principal component analysis, modified mountain clustering method, descent method, and fuzzy logic systems for the damage detection of concrete bridges. Taha and Lucero [32] introduced new techniques based on Bayesian updating and fuzzy sets to improve pattern recognition and damage detection of structures.

In this study, a new acquisition method for modal curvature difference (MCD) is proposed. Firstly, the modal curvature of damaged structure can be calculated through central difference approximation based on mode shape data. Further, modal curvature of undamaged structure can be obtained by Chebyshev polynomial fitting based on the modal curvature at feature nodes of damaged structure. Therefore, MCD parameters can be calculated by use of modal curvatures before and after damage. Subsequently, a fuzzy logic system for damage condition assessment of bridge is constructed using normalized modal curvature difference (NMCD) as input variable. Numerical simulation of a simply supported beam bridge verifies the feasibility of the proposed method.

\section{Theoretical Background}

2.1. Modal Shape Curvature. The curvature of EulerBernoulli beam can be expressed by

$$
\rho=\frac{y^{\prime \prime}}{\left(1+\left(y^{\prime}\right)^{2}\right)^{3 / 2}},
$$

where $\rho$ is the curvature of displacement curve and $y^{\prime}$ and $y^{\prime \prime}$ are the first and second derivatives of displacement function, respectively. Based on the assumption of small slope of beam displacement, the first derivative $y^{\prime}$ is close to zero; thus the denominator in (1) is equal to one. Therefore, the following expression can be used for calculating the curvature of beam:

$$
\rho \approx y^{\prime \prime} \text {. }
$$

Considering that central difference can obtain a more accurate approximation, its calculation results satisfy the project requirements [33]. Therefore, it is widely applied to estimate modal curvatures from the mode shapes in practice. It can be expressed by

$$
\mathrm{MSC}_{r, i}=\frac{\left[\phi_{r}(i-1)+\phi_{r}(i+1)-2 \phi_{r}(i)\right]}{h^{2}},
$$

where MSC represents modal curvature, $r$ represents the mode number, $i$ represents the corresponding node number, $h$ is the element length, and $\phi_{r}(i)$ is the mode shape value for the $i$ th node of the $j$ th mode.

The modal curvature difference (MCD) is obtained by subtracting the undamaged modal curvature vector from the respective damaged one, given by

$$
\mathrm{MCD}=\mathrm{MSC}^{d}-\mathrm{MSC}^{u}
$$

where $\mathrm{MSC}^{d}$ and $\mathrm{MSC}^{u}$ are the modal curvatures for damaged and undamaged structure, respectively. 
2.2. Chebyshev Polynomial Fitting. The Chebyshev polynomials are a sequence of orthogonal polynomials which are related to de Moivre's formula and which can be defined recursively. They are important in approximation theory because they can be used for polynomial interpolation. The resulting interpolation polynomial minimizes the problem of Runge's phenomenon and provides an approximation that is close to the polynomial of best approximation to a continuous function under the maximum norm [34].

2.2.1. Definition of Chebyshev Polynomial. The $m$-order Chebyshev polynomial can be defined by

$$
\begin{gathered}
T_{m}(x)=\cos m \theta \quad(0 \leq \theta \leq \Pi, m=0,1,2, \ldots), \\
x=\cos \theta \quad(0 \leq \theta \leq \Pi,-1 \leq x \leq 1)
\end{gathered}
$$

and its recursive formulas are as follows:

$$
\begin{gathered}
T_{0}(x)=1 ; \\
T_{1}(x)=x \\
T_{n+1}(x)=2 x T_{n}(x)-T_{n-1}(x) .
\end{gathered}
$$

2.2.2. Functional Expression Using Chebyshev Polynomial. An orthogonal group can be constructed through Chebyshev polynomials, and the approximating polynomial of function $f(x)$ at independent variable interval $[-1,1]$ can be expressed by

$$
\begin{aligned}
f(x) & =c_{0}(x) T_{0}(x)+c_{1}(x) T_{1}(x)+\cdots+c_{m-1}(x) T_{m-1}(x) \\
& =\sum_{i=0}^{m-1} c_{i} T_{i}(x),
\end{aligned}
$$

where $T_{0}(x), T_{1}(x), \ldots, T_{m-1}(x)$ are the orthogonal polynomials group and $c_{0}(x), c_{1}(x), \ldots, c_{m}(x)$ are the corresponding coefficients.

\subsubsection{Curve Fitting Procedure Using Chebyshev Polynomial}

(1) Construction of Normalized Interval. If $x_{i}(i=1,2,3$, $\ldots, m) \in[a, b]$, it can be transformed into the normalized interval $[-1,1]$ by

$$
t=\frac{(2 \times x-(a+b))}{(b-a)}, \quad t \in[-1,1]
$$

where $a=\min \left(x_{i}\right), b=\max \left(x_{i}\right)$, and $m$ is the number of $x_{i}$.

(2) Acquisition of Normalized Data Table. Through the construction of normalized interval, the data table for $\left[x_{i}, y_{i}\right]$ can be transformed into $\left[t_{i}, y_{i}\right]$.

(3) Access to Zero Point of m-Order Chebyshev Polynomial. The zero point $\widetilde{t}_{i}$ of $m$-order Chebyshev polynomial can be calculated by

$$
\tilde{t}_{i}=\cos \frac{(2 i-1) \pi}{2(n+1)} \quad(i=1,2, \ldots, n+1),
$$

where $n$ is the degree of the polynomial. Generally, $m=n+1$.

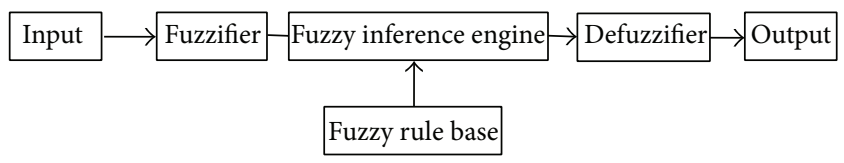

FiguRE 1: Schematic diagram of Mamdani fuzzy logic system.

(4) Acquisition of $\tilde{y}_{i}$ Corresponding to Zero Point $\tilde{t}_{i}$. The $\tilde{y}_{i}$ corresponding to zero point $\tilde{t}_{i}$ in data table $\left[t_{i}, y_{i}\right]$ can be obtained through interpolation method.

(5) Determination of Coefficients $\left(a_{0}(x), a_{1}(x), \ldots, a_{n}(x)\right)$. The $a_{0}(x), a_{1}(x), \ldots, a_{n}(x)$ for orthogonal polynomials group can be calculated by

$$
a_{k}= \begin{cases}\frac{1}{n+1} \sum_{i=1}^{m} \tilde{y}_{i}, & k=0, \\ \frac{2}{n+1} \sum_{i=1}^{m} T_{k}\left(\widetilde{t}_{i}\right) \tilde{y}_{i}, & k=1,2, \ldots, n .\end{cases}
$$

(6) Functional Relationship between $t_{i}$ and $y_{i}$. The data table $\left[t_{i}, y_{i}\right]$ can be expressed by the following function:

$$
\widetilde{\phi}\left(t_{i}\right)=a_{0} T_{0}(t)+a_{1} T_{1}(t)+\cdots+a_{n} T_{n}(t) .
$$

(7) Fitting Error between $y_{i}$ and $\widetilde{\phi}\left(t_{i}\right)$. The Fitting error $\delta$ between $y_{i}$ and $\widetilde{\phi}\left(t_{i}\right)$ can be obtained by the following mean square error function:

$$
\delta=\sqrt{\sum_{i=1}^{m}\left(\phi\left(t_{i}\right)-y_{i}\right)^{2}} .
$$

2.3. Fuzzy Logic Systems. A fuzzy logic system (FLS) is an information processing system that simulates the fuzzy inference ability of human brain. It is able to simultaneously handle numerical data and linguistic knowledge. It is a nonlinear mapping of an input data vector into a scholar output. Fuzzy set is characterized by a membership function which takes on values in the interval $[0,1]$. The Mamdani system and Takagi-Sugeno system are the most widely used fuzzy logic systems. In the Mamdani system, fuzzy sets are used both in the antecedents and in the consequents of the if -then rules, while the consequents are represented by functions in Takagi-Sugeno system. In this paper, the Mamdani system is adopted to carry out the damage identification. The fuzzy logic controller is composed of fuzzification, fuzzy inference, and defuzzification as shown in Figure 1.

\section{Numerical Example}

A numerical analysis is performed on a simply supported bridge as shown in Figure 2. The model consists of 21 nodes and 20 elements with equal element length $\left(L^{\mathrm{EL}}=1 \mathrm{~m}\right)$ and uniform bending rigidity $\left(E I=1.155 \times 10^{7} \mathrm{kN} \cdot \mathrm{m}^{2}\right)$.

According to the theory of modal analysis, natural frequency and modal shape are closely related with rigidity $(r)$ 


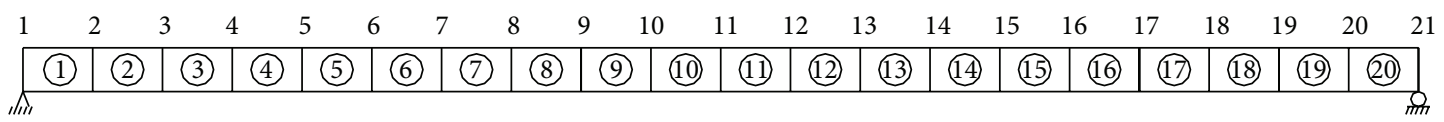

FIgURE 2: Model of simply supported bridge.

and mass $(m)$ of bridge. In general, the damage of bridge does not alter its mass but the rigidity. Therefore, the reduction of bridge rigidity caused by damage is the main factor leading to modal variation, as follows [35]:

$$
r_{i}=1-\frac{k_{i, d}}{k_{i, u}}
$$

where $i$ is the number of damaged elements and $k_{i, u}, k_{i, d}$ represent the rigidity of undamaged and damaged elements, respectively.

Taking the rectangular beam, for example, $h$ is the section height and $b$ is the section width. The rigidity $k$ of this section can be expressed by

$$
k=E \cdot I=E \times \frac{b \times h^{3}}{12}
$$

where $E$ is elastic modulus and $I$ is bending moment of inertia.

As can be seen from (14), the rigidity of bridge contains two aspects, that is, elasticity and section size $(b$ and $h)$. In the present research, there are usually two simulation methods for damage: one assumes that the section size of bridge is changed, while the other assumes that the elasticity of bridge material is altered. In this paper, the latter method is adopted and the damage parameter $\alpha_{i}$ is defined by

$$
\alpha_{i}=1-\frac{E_{i, d}}{E_{i, u}}
$$

where $i$ is the number of damaged elements and $E_{i, u}, E_{i, d}$ represent elasticity of undamaged and damaged elements, respectively.

3.1. Modal Curvature-Based Damage Localization without Baseline Model Parameters. Firstly, modal shape of damaged structure can be obtained by finite element analysis of bridge. It can be expressed by $\left[N, \phi_{i}\right]: N(1,2, \ldots, 21)$ is the node number and $\phi_{i}$ is the $i$ th displacement mode shape, and the first vertical bending mode $(i=1)$ is discussed in this paper. The modal curvature for damaged structure can be calculated through central difference approximation.

Secondly, the nodes related to damaged elements are excluded and the modal curvatures at remaining nodes $\left[N^{\prime}, \phi^{\prime}\right]$ are fitted through Chebyshev polynomial as shown in (11). And the fitting effect can be evaluated by (12). The normalized intervals are listed in Table 1 . In this paper, sixorder Chebyshev orthogonal polynomials group are used for curve fitting, and the zero points $\tilde{t}_{i}$ are listed in Table 2.

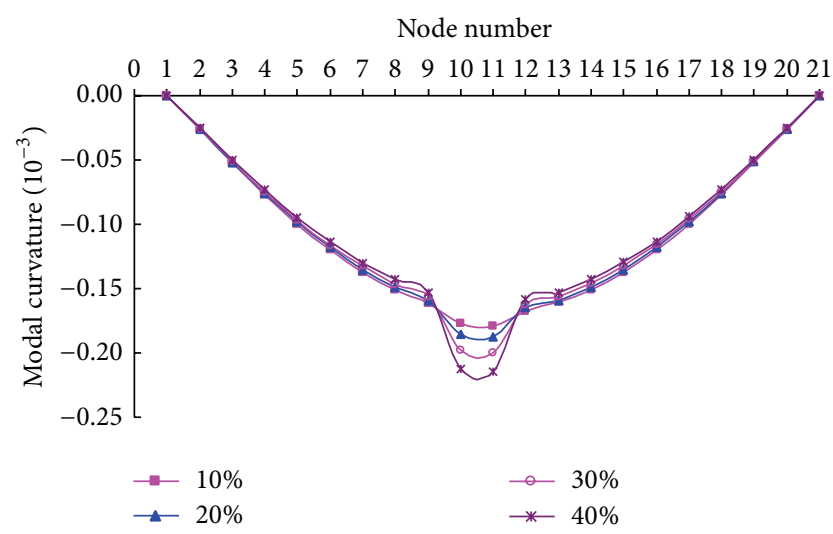

FIGURE 3: Modal curvatures of element 10 with damage severity $(10 \%, 20 \%, 30 \%$, and $40 \%)$.

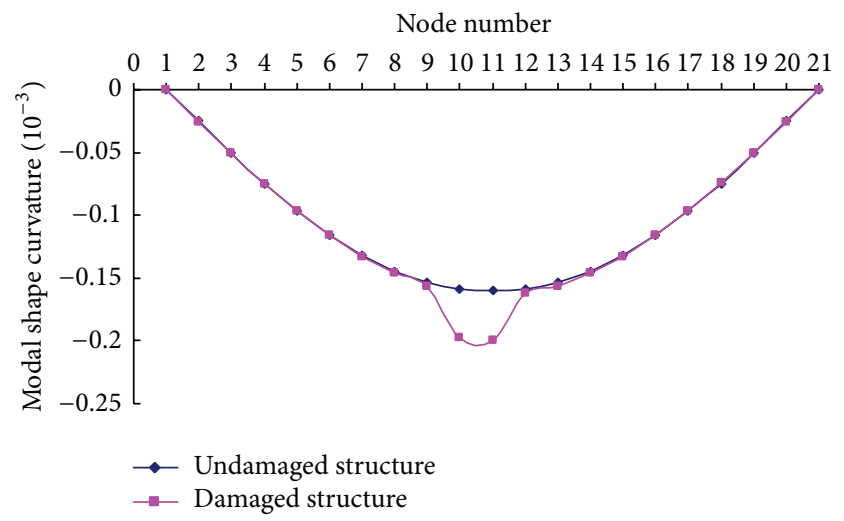

FIGURE 4: Modal curvature of undamaged structure obtained by Chebyshev polynomial fitting for damage identification with single location.

Finally, modal curvature difference is acquired based on the above results of modal curvature for undamaged and damaged structure.

3.1.1. Damage Localization for Single Location. Taking the damage localization of element 10 with rigidity reduction (10\%, 20\%, 30\%, and 40\%), for example, modal curvatures at each node obtained by central difference approximation for damaged structure are shown in Figure 3.

The modal curvatures of undamaged structure corresponding to each damage severity are obtained by Chebyshev polynomial fitting by use of the mode shape data at nodes ( 1 , $2,3,4,5,6,7,8,9,12,13,14,15,16,17,18,19,20$, and 21). Taking the damage severity $30 \%$, for example, the modal curvatures of undamaged and damaged structure are shown in Figure 4. 
TABLE 1: Normalized interval for simply supported bridge with 21 nodes.

\begin{tabular}{lccccccccccccccccccccc}
\hline Node number & 1 & 2 & 3 & 4 & 5 & 6 & 7 & 8 & 9 & 10 & 11 & 12 & 13 & 14 & 15 & 16 & 17 & 18 & 19 & 20 & 21 \\
\hline Normalized interval & -1 & -0.9 & -0.8 & -0.7 & -0.6 & -0.5 & -0.4 & -0.3 & -0.2 & -0.1 & 0 & 0.1 & 0.2 & 0.3 & 0.4 & 0.5 & 0.6 & 0.7 & 0.8 & 0.9 & 1 \\
\hline
\end{tabular}

TABLE 2: Zero points for six-order Chebyshev polynomial fitting.

\begin{tabular}{lccccccc}
\hline Number & 1 & 2 & 3 & 4 & 5 & 6 & 7 \\
\hline$\widetilde{t_{i}}$ & 0.9749 & 0.7818 & 0.4339 & 0 & -0.4339 & -0.7818 & -0.9749 \\
\hline
\end{tabular}

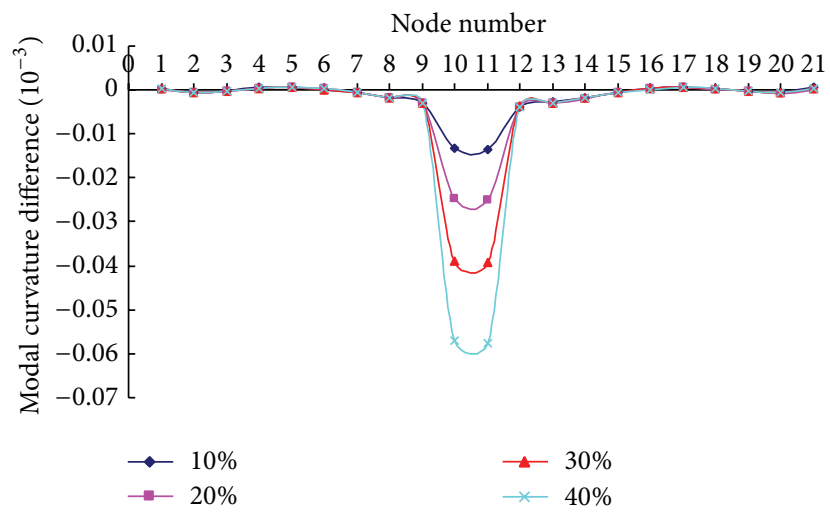

Figure 5: Modal curvature difference of element 10 with damage severity $(10 \%, 20 \%, 30 \%$, and $40 \%)$.

The fitting function of modal curvature at damage severity $30 \%$ for undamaged structure is shown as follows:

$$
\begin{aligned}
f= & -10^{-3} \\
& \times\left(0.029 \times t^{6}-0.0148 \times t^{4}-0.1739 \times t^{2}+0.1602\right),
\end{aligned}
$$

where $f$ is the modal curvature at damage severity $30 \%$ for undamaged structure and $t$ is the normalized interval obtained by (8).

The fitting error $\delta$ is calculated according to (12), and $\delta=0.000485$; it reveals that the Chebyshev polynomial fitting possesses favorable accuracy.

Modal curvature differences of element 10 with rigidity reduction $(10 \%, 20 \%, 30 \%$, and $40 \%)$ are calculated based on the above results, and they are shown in Figure 5.

3.1.2. Damage Localization for Multiple Locations. Taking the damage localization of elements 5,10 , and 16 , for example, damage cases are shown in Table 3.

Modal curvature at each node calculated by central difference approximation for damaged structure is shown in Figure 6.

The modal curvatures of undamaged structure are obtained by Chebyshev polynomial fitting using the mode shape data at nodes $(1,2,3,4,7,8,9,12,13,14,15,18,19,20$,

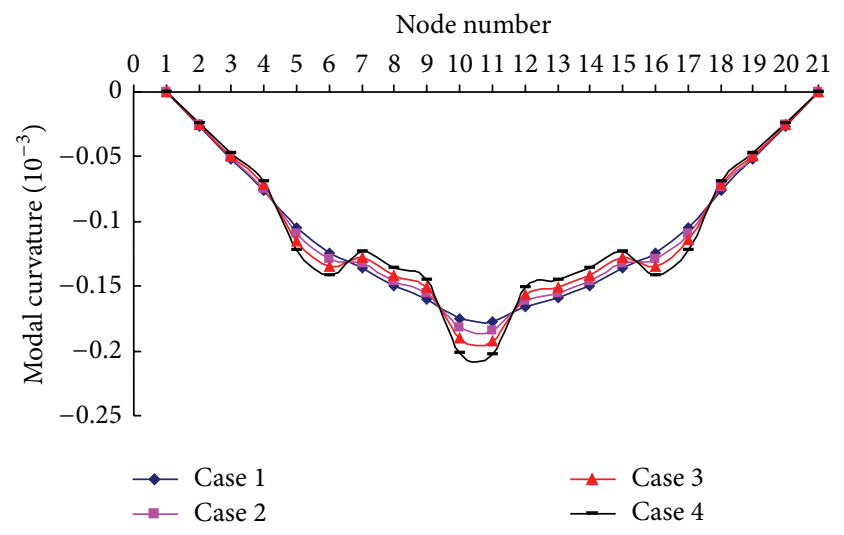

FIGURE 6: Modal curvature for multiple damage locations.

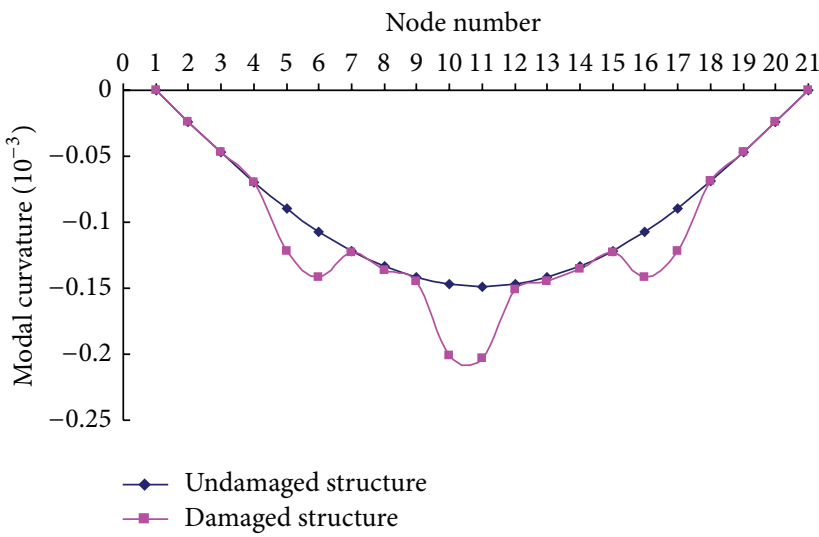

Figure 7: Modal curvature of undamaged structure obtained by Chebyshev polynomial fitting for damage identification with multiple locations.

and 21). Taking case 4, for example, the modal curvatures of undamaged and damaged structure are shown in Figure 7.

The fitting function of modal curvature of case 4 for undamaged structure is shown as follows:

$$
\begin{aligned}
f= & -10^{-3} \\
& \times\left(0.0137 \times t^{6}-0.086 \times t^{4}-0.1817 \times t^{2}+0.1596\right) .
\end{aligned}
$$

And the fitting error $\delta=0.0001597$.

Modal curvature differences for all cases in Table 3 are calculated based on the above results, and they are shown in Figure 8. 
TABLE 3: Cases for damage localization with multiple locations.

\begin{tabular}{lcccc}
\hline Case number & 1 & 2 & 3 & 4 \\
\hline Damage severity & $10 \%, 10 \%, 10 \%$ & $20 \%, 20 \%, 20 \%$ & $30 \%, 30 \%, 30 \%$ & $40 \%, 40 \%, 40 \%$ \\
\hline
\end{tabular}

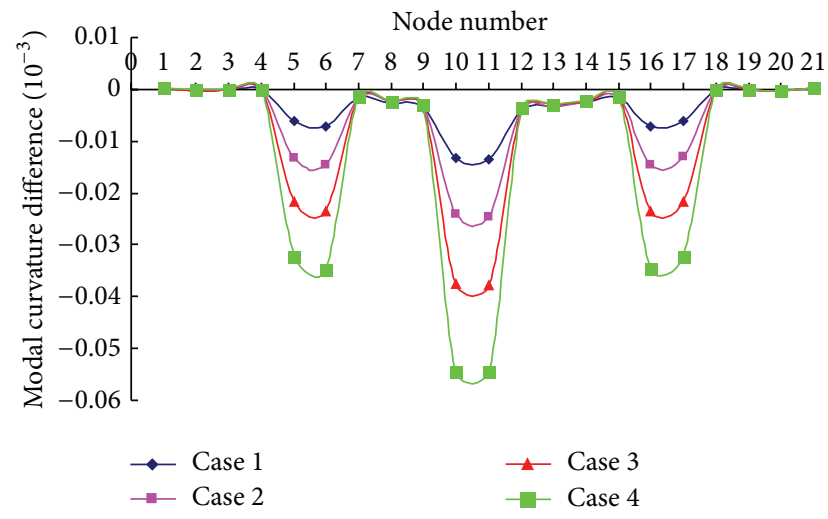

FIGURE 8: Modal curvature difference for damage localization with multiple locations.

\subsection{Fuzzy Logic-Based Damage Condition Assessment}

\subsubsection{Calculation Process of Fuzzy Logic}

(1) Inputs and Outputs. The objective of fuzzy logic is to map an input vector represented by $x$ to an output one represented by $y$. In this paper, the vectors $x$ and $y$ can be expressed by

$$
\begin{gathered}
x=\left(x_{1}, x_{2}, \ldots, x_{m}\right), \\
x_{j}=\frac{\left(\operatorname{MCD}_{j}^{i}-\min \left(\underset{n=1}{p} \operatorname{MCD}_{n}^{i}\right)\right)}{\left(\max \left(\begin{array}{c}
p \\
\operatorname{MCD}_{n}^{i} \\
n=1
\end{array}\right)-\min \left(\operatorname{MCD}_{n}^{p}\right)\right)}, \\
y=\alpha=1-\frac{E_{i, d}}{E_{i, u}}, \\
y=f(x),
\end{gathered}
$$

where $x_{j}$ is the $j$ th input variable which is the normalized modal curvature difference (NMCD); $\mathrm{MCD}_{j}^{i}$ is the modal curvature difference at node $j$ of mode $i ; \alpha$ is the damage severity; and $E_{i, d}$ and $E_{i, u}$ are the same with (15).

(2) Fuzzification. The fuzzification comprises the process of transforming crisp values into grades of membership for linguistic terms of fuzzy sets. The membership function is used to associate a grade to each linguistic term.

Inputs of the fuzzy logic system are NMCD and outputs are structural damage degree of elements. For input variables, we define nine membership functions to transform NMCD into linguistic terms of fuzzy sets. It is considered as a linguistic variable. It can be decomposed into a set of terms: $\mathrm{T}(\mathrm{NMCD})=\{$ negligible, very low, low, low medium,

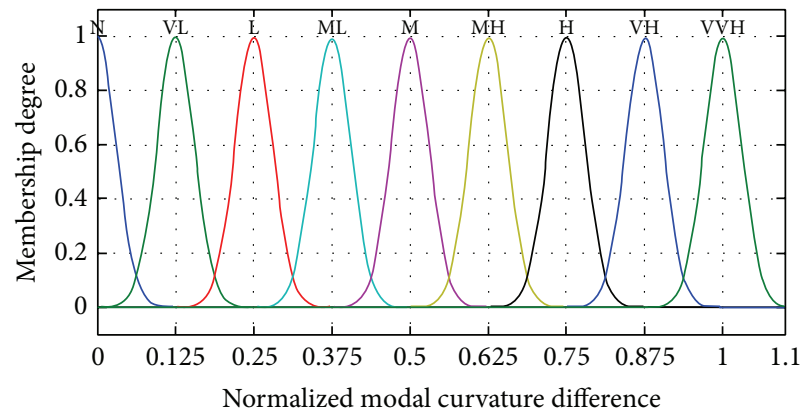

FIgURE 9: Membership function for input variables.

TABLE 4: Fuzzy sets for output measurements.

\begin{tabular}{lllc}
\hline Damage condition & $a$ & $b$ & $c$ \\
\hline No damage & 4 & 4 & 0 \\
Slight damage & 4 & 4 & 10 \\
Moderate damage & 4 & 4 & 20 \\
Severe damage & 4 & 4 & 30 \\
Catastrophic damage & 4 & 4 & 40 \\
\hline
\end{tabular}

medium, medium high, high, very high, very very high $\}=$ $\{\mathrm{N}, \mathrm{VL}, \mathrm{L}, \mathrm{LM}, \mathrm{M}, \mathrm{MH}, \mathrm{H}, \mathrm{VH}, \mathrm{VVH}\}$.

Fuzzy sets with Gaussian membership functions are used for the input variables. These fuzzy sets can be defined using the following equation and they are shown in Figure 9:

$$
\mu(x)=e^{-0.5((x-m) / \sigma)^{2}}
$$

where $m$ is the midpoint of the fuzzy set and $\sigma$ is the standard deviation associated with the variable. The midpoints are selected to span the region ranging from an undamaged bridge to one with significant damage, while the standard deviations are selected in order to guarantee the enough width to capture the variations of the input variables. Therefore, the reasonable selection of $m$ and $\sigma$ is very important for the performance of the fuzzy logic systems.

For output variables, we define five membership functions to transform the damage degree into linguistic terms of fuzzy sets. For example, "element 10" is considered as a linguistic variable and it is decomposed into a set of terms: $\mathrm{T}$ (element 10$)=\{$ undamaged, slight damage, moderate damage, severe damage, catastrophic damage\}.

The other output variables are fuzzified in a similar manner.

Fuzzy sets with Bell functions are used for the output variables. These fuzzy sets can be defined using the following equation:

$$
\mu(y)=\frac{1}{1+|(y-c) / a|^{2 b}}
$$


TABLE 5: Fuzzy rules for damage condition assessment of single location.

\begin{tabular}{lccccc}
\hline \multirow{2}{*}{ Node number } & & \multicolumn{2}{c}{ NMCD } & \\
& No damage & Slight damage & Moderate damage & Severe damage & Catastrophic damage \\
\hline 10 & $\mathrm{~N}$ & $\mathrm{VL}$ & ML & MH & VVH \\
11 & $\mathrm{~N}$ & $\mathrm{VL}$ & ML & MH & VVH \\
\hline
\end{tabular}

TABLE 6: Test samples for fuzzy system of damage condition assessment with single location.

\begin{tabular}{ll}
\hline Damaged element & Damage condition \\
\hline 10 & $\begin{array}{l}\text { 2\% (no damage), } 8 \% \text { (slight damage), 10\% (slight damage), 13\% (slight damage), 18\% (moderate damage), 20\% } \\
\text { (moderate damage), 22\% (moderate damage), 29\% (severe damage), 30\% (severe damage), 32\% (severe } \\
\text { damage), 38\% (catastrophic damage), and 40\% (catastrophic damage) }\end{array}$ \\
\hline
\end{tabular}

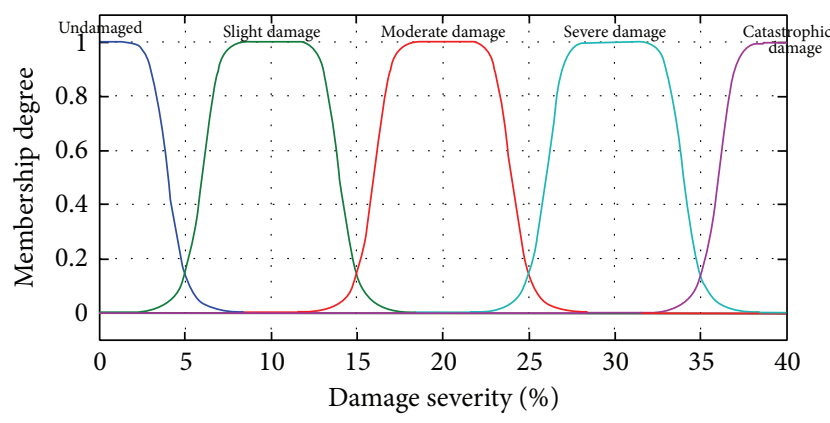

FIGURE 10: Schematic diagram of fuzzy sets for output measurements.

where $[a, b, c]$ are the variables that control the shape of function.

The parameters of Bell function used in this paper are shown in Table 4 and Figure 10.

(3) Rule Base. Once the input and output variables and their membership functions are defined, we can design the rule base which is composed of "if < antecedents> then $<$ consequents >" rules. The antecedents and consequents are the input and output variables, respectively.

Rules for a fuzzy logic system are obtained by fuzzification of the numerical values obtained from finite element analysis using the following procedure.

(i) The ith input variable corresponding to a given structural fault is fuzzified and the corresponding membership degrees can be obtained. Therefore, each measurement has nine grades of membership based on the linguistic terms.

(ii) Each input variable is then assigned to the fuzzy set with the maximum degree of membership.

(iii) One rule is obtained for each fault by relating the fuzzified input variable with maximum membership degree of the fault.

3.2.2. Damage Condition Assessment for Single Location. Taking the damage condition assessment of element 10, for example, NMCD at nodes 10 and 11 are adopted as the input variables of fuzzy logic system, and the rule base is formulated and presented in Table 5.

In order to verify the inference ability of the established fuzzy system, test samples are selected and listed in Table 6 and their damage conditions corresponding to severity are also presented. The damage identification results for these test samples using fuzzy system are demonstrated in Table 7.

Damage condition of test samples can be determined through the maximum membership degree. As can be seen from Table 7, fuzzy systems can correctly identify the damage condition for all test samples. It reveals that the fuzzy systems possess favorable inference ability for damage condition assessment of single location.

\subsubsection{Damage Condition Assessment for Multiple Locations.} Taking the damage condition assessment of elements 5, 10, and 16, for example, NMCD at nodes 5, 6, 10, 11, 16, and 17 are adopted as the input variables of fuzzy system, and the rule base is formulated and presented in Table 8 .

In order to verify the inference ability of the established fuzzy systems of damage condition assessment with multiple locations, test samples are listed in Table 9, and their damage conditions corresponding to severity are also presented.

The damage severities listed in Table 9 can be fuzzified according to the membership function shown in Figure 10. And the linguistic variable corresponding to $12 \%$ is "slight damage," while $27 \%$ is "severe damage," $39 \%$ is "catastrophic damage," $28 \%$ is "severe damage," and $32 \%$ is "severe damage." The damage identification results for these test samples using fuzzy system are demonstrated in Table 10.

As can be seen from Table 10, fuzzy logic system can correctly identify the damage condition for all test samples; it reveals that the fuzzy system possesses favorable inference ability for damage condition assessment of multiple locations.

\section{Conclusions}

In practice, the baseline model parameters are difficult to obtain and their accuracy will affect the damage identification results. In order to solve this problem, Chebyshev polynomial 
TABLE 7: Membership degree of test samples identified by fuzzy systems.

\begin{tabular}{|c|c|c|c|c|c|c|c|c|c|c|c|c|}
\hline \multirow{2}{*}{ Damage condition } & \multicolumn{12}{|c|}{ Damage severity (\%) } \\
\hline & 2 & 8 & 10 & 13 & 18 & 20 & 22 & 29 & 30 & 32 & 38 & 40 \\
\hline No damage & 0.99 & 0 & 0 & 0 & 0 & 0 & 0 & 0 & 0 & 0 & 0 & 0 \\
\hline Slight damage & 0 & 1 & 1 & 1 & 0 & 0 & 0 & 0 & 0 & 0 & 0 & 0 \\
\hline Moderate damage & 0 & 0 & 0 & 0 & 1 & 1 & 1 & 0 & 0 & 0 & 0 & 0 \\
\hline Severe damage & 0 & 0 & 0 & 0 & 0 & 0 & 0 & 1 & 1 & 1 & 0.02 & 0 \\
\hline Catastrophic damage & 0 & 0 & 0 & 0 & 0 & 0 & 0 & 0 & 0 & 0 & 0.8 & 1 \\
\hline
\end{tabular}

TABLE 8: Fuzzy rules for damage condition assessment of multiple locations.

\begin{tabular}{|c|c|c|c|c|c|c|}
\hline \multirow{2}{*}{ Damage condition } & \multicolumn{6}{|c|}{ Node number } \\
\hline & 5 & 6 & 10 & 11 & 16 & 17 \\
\hline $\begin{array}{l}\text { 5-slight damage; } \\
\text { 10-slight damage; } \\
\text { 16-slight damage }\end{array}$ & VVH & VVH & VVH & VVH & VVH & VVH \\
\hline $\begin{array}{l}\text { 5-slight damage; } \\
\text { 10-moderate damage; } \\
\text { 16-slight damage }\end{array}$ & VVH & VVH & $\mathrm{H}$ & $\mathrm{H}$ & VVH & $\mathrm{VVH}$ \\
\hline $\begin{array}{l}5 \text {-slight damage; } \\
\text { 10-severe damage; } \\
16 \text {-slight damage }\end{array}$ & VVH & VVH & ML & ML & $\mathrm{VVH}$ & $\mathrm{VVH}$ \\
\hline $\begin{array}{l}\text { 5-slight damage; } \\
\text { 10-catastrophic damage; } \\
\text { 16-slight damage }\end{array}$ & VVH & VVH & $\mathrm{N}$ & $\mathrm{N}$ & VVH & $\mathrm{VVH}$ \\
\hline $\begin{array}{l}\text { 5-severe damage; } \\
\text { 10-slight damage; } \\
\text { 16-slight damage }\end{array}$ & ML & ML & VVH & VVH & VVH & $\mathrm{VVH}$ \\
\hline $\begin{array}{l}\text { 5-severe damage; } \\
\text { 10-slight damage; } \\
\text { 16-moderate damage }\end{array}$ & ML & ML & VVH & VVH & $\mathrm{H}$ & $\mathrm{H}$ \\
\hline $\begin{array}{l}\text { 5-severe damage; } \\
\text { 10-slight damage; } \\
\text { 16-severe damage }\end{array}$ & ML & ML & VVH & VVH & ML & ML \\
\hline $\begin{array}{l}\text {-severe damage; } \\
\text { 10-slight damage; } \\
\text { 16-catastrophic damage }\end{array}$ & ML & ML & VVH & VVH & $\mathrm{N}$ & $\mathrm{N}$ \\
\hline $\begin{array}{l}\text { 5-moderate damage; } \\
\text { 10-moderate damage; } \\
\text { 16-moderate damage }\end{array}$ & $\mathrm{H}$ & $\mathrm{H}$ & $\mathrm{H}$ & $\mathrm{H}$ & $\mathrm{H}$ & $\mathrm{H}$ \\
\hline $\begin{array}{l}5 \text {-severe damage; } \\
10 \text {-severe damage; } \\
16 \text {-severe damage }\end{array}$ & ML & ML & ML & ML & M & $\mathrm{M}$ \\
\hline $\begin{array}{l}\text { 5-catastrophic damage; } \\
\text { 10-catastrophic damage; } \\
\text { 16-catastrophic damage }\end{array}$ & $\mathrm{N}$ & $\mathrm{N}$ & $\mathrm{N}$ & $\mathrm{N}$ & VL & $\mathrm{VL}$ \\
\hline
\end{tabular}

TABLE 9: Test samples for fuzzy system of damage condition assessment with multiple locations.

Damaged element

5-10-16
Damage severity (\%)

20-20-20; 30-30-30; 40-40-40; 10-12-10; 10-27-10; 10-39-10; $30-10-12 ; 30-10-28 ; 30-10-32$ 
TABLE 10: Identification results of fuzzy systems for multiple locations.

Damage severity (\%)

Damage condition

\begin{tabular}{lc}
\hline $20-20-20$ & 5-moderate damage; 10-moderate damage; 16-moderate damage \\
\hline $30-30-30$ & 5-severe damage; 10-severe damage; 16-severe damage \\
\hline $40-40-40$ & 5-catastrophic damage; 10-catastrophic damage; \\
& 16-catastrophic damage \\
\hline $10-12-10$ & 5-slight damage; 10-slight damage; 16-slight damage \\
\hline $10-27-10$ & 5-slight damage; 10-severe damage; 16-slight damage \\
\hline $10-39-10$ & 5-slight damage; 10-catastrophic damage; 16-slight damage \\
\hline $30-10-12$ & 5-severe damage; 10-slight damage; 16-slight damage \\
\hline $30-10-28$ & 5-severe damage; 10-slight damage; 16-severe damage \\
\hline
\end{tabular}

fitting and fuzzy logic-based damage identification method are proposed for damage identification of bridge without considering baseline data. Numerical simulation of a simply supported beam bridge is used to verify the feasibility of the proposed method.

As for MCD-based damage localizing, cases are established for damage identification with single and multiple locations. Modal curvature of damaged structure can be calculated through central difference approximation. By excluding the nodes related to damaged elements, modal curvature of undamaged structure is obtained through sixorder Chebyshev polynomial fitting. Error analysis reveals that it possesses favorable accuracy. Subsequently, MCD parameters can be calculated by use of modal curvature before and after damage. The results indicate that it is effective for damage localizing.

As for fuzzy logic system-based damage condition assessment, NMCD is used as input variable and damage severity is output variable. Gaussian and Bell functions are selected as membership functions for input and output variables, respectively. Fuzzy logic systems for damage condition assessment of single and multiple locations are constructed, and the identification results for test samples demonstrate that they possess satisfactory inference ability.

Compared with traditional finite element modeling of bridge before and after damage, the proposed method can realize damage identification depending only on the modal properties of damaged structure. It overcomes the shortcoming that the baseline model is difficult to obtain in practice. But on the other hand a higher requirement of test accuracy for the dynamic response of damaged bridge is put forward, and accurate measurement must be guaranteed in practical application.

\section{Conflict of Interests}

The authors declare that there is no conflict of interests regarding the publication of this paper.

\section{Acknowledgments}

The authors express their appreciation for the financial support of National Natural Science Foundation of China under
Grants nos. 51408258, 51378236, and 51278222; China Postdoctoral Science Foundation funded project (2014M560237); Fundamental Research Funds for the Central Universities and Science \& Technology Development Program of Jilin Province (20140203002SF).

\section{References}

[1] S. W. Doebling, C. R. Farrar, M. B. Prime et al., "A review of damage identification methods that examine changes in dynamic properties," Shock and Vibration Digest, vol. 30, pp. 91-105, 1998.

[2] E. P. Carden and P. Fanning, "Vibration based condition monitoring: a review," Structural Health Monitoring, vol. 3, no. 4, pp. 355-377, 2004.

[3] O. S. Salawu, "Detection of structural damage through changes in frequency: a review," Engineering Structures, vol. 19, no. 9, pp. 718-723, 1997.

[4] Z. R. Lu, J. K. Liu, M. Huang, and W. H. Xu, "Identification of local damages in coupled beam systems from measured dynamic responses," Journal of Sound and Vibration, vol. 326, no. 1-2, pp. 177-189, 2009.

[5] P. Cawley and R. D. Adams, "The location of defects in structures from measurements of natural frequencies," The Journal of Strain Analysis for Engineering Design, vol. 14, no. 2, pp. 49-57, 1979.

[6] M. A.-B. Abdo and M. Hori, "A numerical study of structural damage detection using changes in the rotation of mode shapes," Journal of Sound and Vibration, vol. 251, no. 2, pp. 227239, 2002.

[7] A. K. Pandey, M. Biswas, and M. M. Samman, "Damage detection from changes in curvature mode shapes," Journal of Sound and Vibration, vol. 145, no. 2, pp. 321-332, 1991.

[8] Z. Y. Shi, S. S. Law, and L. M. Zhang, "Structural damage localization from modal strain energy change," Journal of Sound and Vibration, vol. 218, no. 5, pp. 825-844, 1998.

[9] Z. Zhang and A. E. Aktan, "Application of modal flexibility and its derivatives in structural identification," Research in Nondestructive Evaluation, vol. 10, no. 1, pp. 43-61, 1998.

[10] M. S. Cao and P. Z. Qiao, "Novel Laplacian scheme and multiresolution modal curvatures for structural damage identification," Mechanical Systems and Signal Processing, vol. 23, no. 4, pp. 1223-1242, 2009.

[11] A.-M. Yan, G. Kerschen, P. de Boe, and J.-C. Golinval, "Structural damage diagnosis under varying environmental 
conditions-part I: a linear analysis," Mechanical Systems and Signal Processing, vol. 19, no. 4, pp. 847-864, 2005.

[12] V. Meruane and W. Heylen, "Structural damage assessment under varying temperature conditions," Structural Health Monitoring, vol. 11, no. 3, pp. 345-357, 2012.

[13] S. N. Shoukry, G. W. William, B. Downie, and M. Y. Riad, "Effect of moisture and temperature on the mechanical properties of concrete," Construction and Building Materials, vol. 25, no. 2, pp. 688-696, 2011.

[14] C. P. Ratcliffe, "Damage detection using a modified laplacian operator on mode shape data," Journal of Sound and Vibration, vol. 204, no. 3, pp. 505-517, 1997.

[15] D. Wu and S. S. Law, "Damage localization in plate structures from uniform load surface curvature," Journal of Sound and Vibration, vol. 276, no. 1-2, pp. 227-244, 2004.

[16] M. K. Yoon, D. Heider, J. W. Gillespie Jr., C. P. Ratcliffe, and R. M. Crane, "Local damage detection using the two-dimensional gapped smoothing method," Journal of Sound and Vibration, vol. 279, no. 1-2, pp. 119-139, 2005.

[17] S. C. Zhong and S. O. Oyadiji, "Crack detection in simply supported beams without baseline modal parameters by stationary wavelet transform," Mechanical Systems and Signal Processing, vol. 21, no. 4, pp. 1853-1884, 2007.

[18] M.-K. Yoon, D. Heider, J. W. Gillespie Jr., C. P. Ratcliffe, and R. M. Crane, "Local damage detection with the global fitting method using mode shape data in notched beams," Journal of Nondestructive Evaluation, vol. 28, no. 2, pp. 63-74, 2009.

[19] R. Rodríguez, J. A. Escobar, and R. Gómez, "Damage detection in instrumented structures without baseline modal parameters," Engineering Structures, vol. 32, no. 6, pp. 1715-1722, 2010.

[20] J. M. Ko, Z. G. Sun, and Y. Q. Ni, "Multi-stage identification scheme for detecting damage in cable-stayed Kap Shui Mun Bridge," Engineering Structures, vol. 24, no. 7, pp. 857-868, 2002.

[21] M. Sahin and R. A. Shenoi, "Quantification and localisation of damage in beam-like structures by using artificial neural networks with experimental validation," Engineering Structures, vol. 25, no. 14, pp. 1785-1802, 2003.

[22] J. J. Lee, J. W. Lee, J. H. Yi, C. B. Yun, and H. Y. Jung, "Neural networks-based damage detection for bridges considering errors in baseline finite element models," Journal of Sound and Vibration, vol. 280, no. 3-5, pp. 555-578, 2005.

[23] N. Bakhary, H. Hao, and A. J. Deeks, "Damage detection using artificial neural network with consideration of uncertainties," Engineering Structures, vol. 29, no. 11, pp. 2806-2815, 2007.

[24] W. T. Yeung and J. W. Smith, "Damage detection in bridges using neural networks for pattern recognition of vibration signatures," Engineering Structures, vol. 27, no. 5, pp. 685-698, 2005.

[25] H.-B. Liu and Y.-B. Jiao, "Application of genetic algorithmsupport vector machine (GA-SVM) for damage identification of bridge," International Journal of Computational Intelligence and Applications, vol. 10, no. 4, pp. 383-397, 2011.

[26] J. M. Benítez, J. L. Castro, and I. Requena, "Are artificial neural networks black boxes?" IEEE Transactions on Neural Networks, vol. 8, no. 5, pp. 1156-1164, 1997.

[27] F. S. Mjalli, S. Al-Asheh, and H. E. Alfadala, "Use of artificial neural network black-box modeling for the prediction of wastewater treatment plants performance," Journal of Environmental Management, vol. 83, no. 3, pp. 329-338, 2007.

[28] R. Ganguli, "A fuzzy logic system for ground based structural health monitoring of a helicopter rotor using modal data," Journal of Intelligent Material Systems and Structures, vol. 12, no. 6, pp. 397-407, 2001.
[29] P. M. Pawar and R. Ganguli, "Genetic fuzzy system for online structural health monitoring of composite helicopter rotor blades," Mechanical Systems and Signal Processing, vol. 21, no. 5, pp. 2212-2236, 2007.

[30] M. Chandrashekhar and R. Ganguli, "Uncertainty handling in structural damage detection using fuzzy logic and probabilistic simulation," Mechanical Systems and Signal Processing, vol. 23, no. 2, pp. 384-404, 2009.

[31] Z. Zhao and C. Chen, "A fuzzy system for concrete bridge damage diagnosis," Computers \& Structures, vol. 80, no. 7-8, pp. 629-641, 2002.

[32] M. M. R. Taha and J. Lucero, "Damage identification for structural health monitoring using fuzzy pattern recognition," Engineering Structures, vol. 27, no. 12, pp. 1774-1783, 2005.

[33] D. R. Lynch, Numerical Partial Differential Equations for Environmental Scientists and Engineers, 2005.

[34] J. H. Mathews and K. D. Fink, Numerical Methods: Using Matlab, Jay Print Pack Private Limited, New Delhi, India, 2005.

[35] H. B. Liu, Y. B. Jiao, and Y. F. Gong, "A fuzzy logic-based damage identification method for simply-supported bridge using modal shape ratios," International Journal of Computational Intelligence Systems, vol. 5, no. 4, pp. 627-638, 2012. 

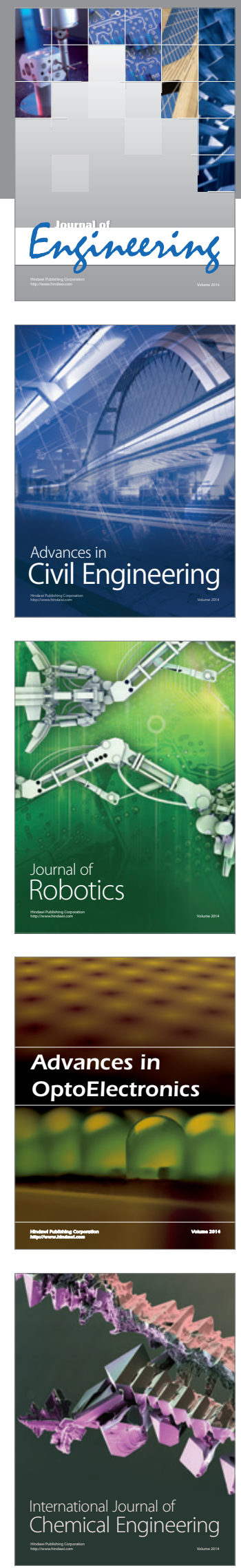

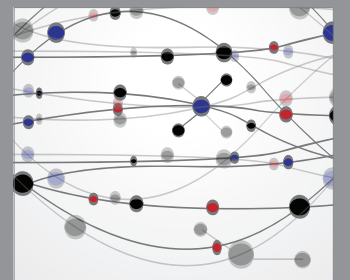

The Scientific World Journal
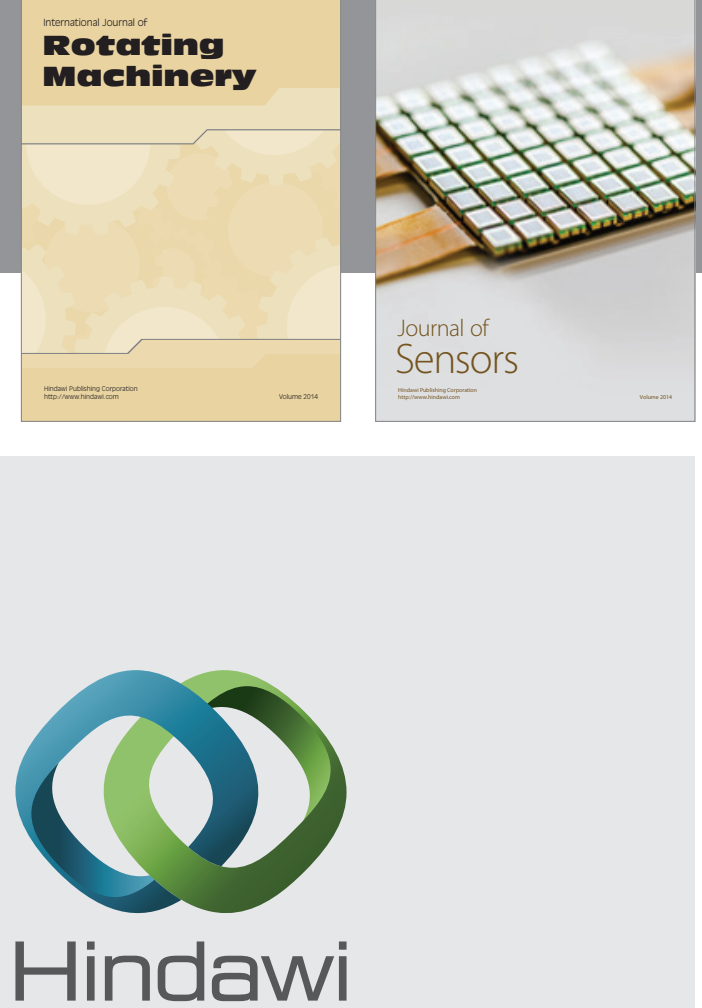

Submit your manuscripts at http://www.hindawi.com
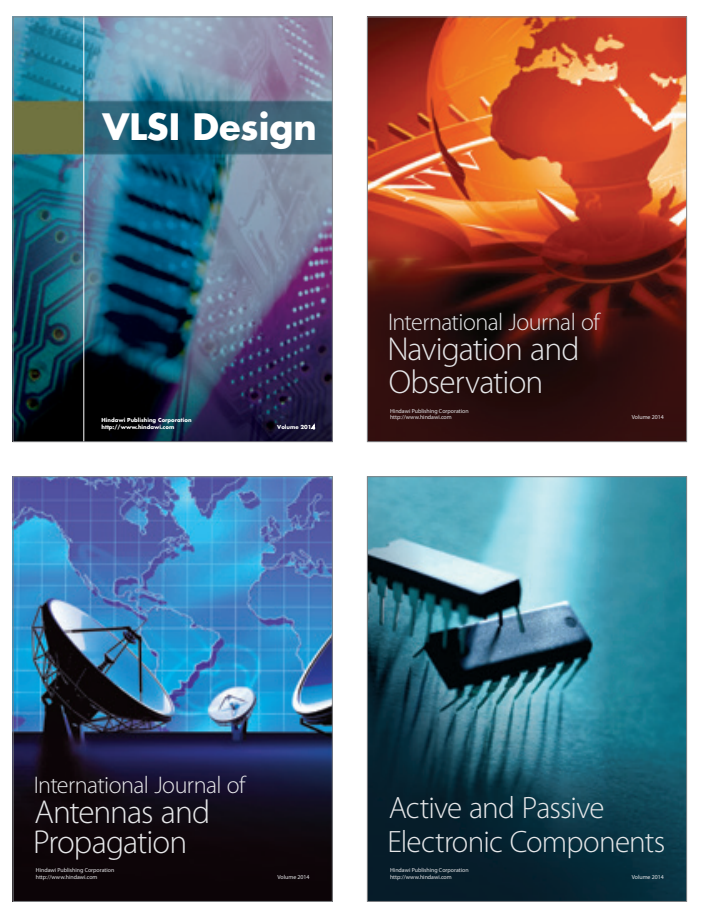
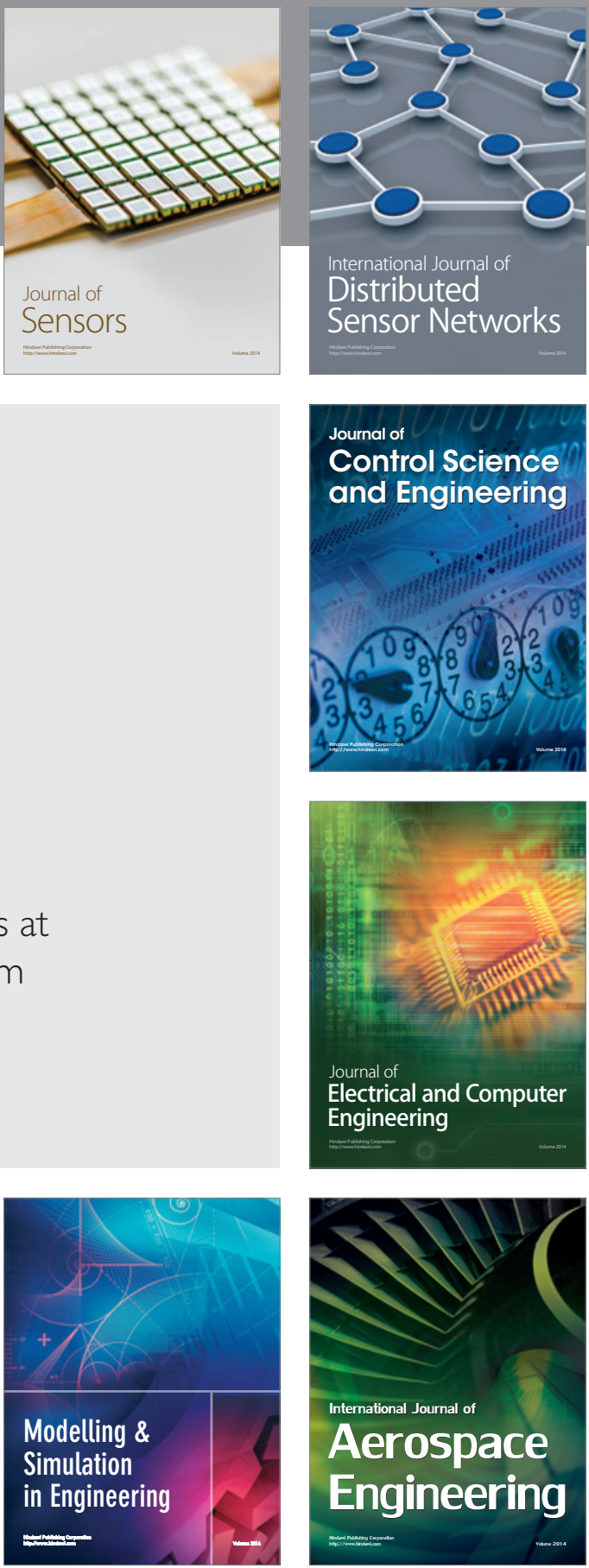

Journal of

Control Science

and Engineering
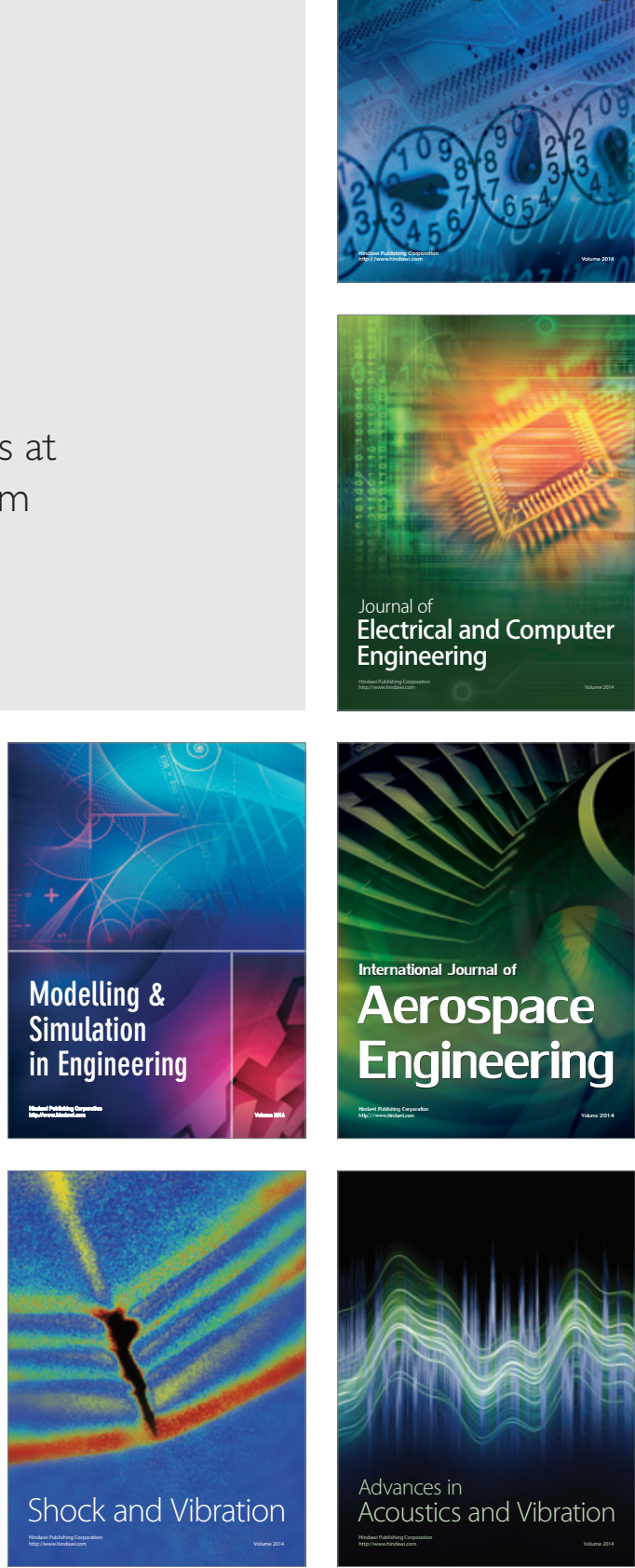